\title{
Comparison of Reverse Shoulder Arthroplasty and Hemiarthroplasty for Proximal Humeral Fractures: What about Functional Outcome? Reverse versus Hemiarthroplasty in Shoulder Fractures
}

\author{
Hamdi Kaziz'1,2, Mohamed Amine Triki'1,2, Sofien Benzarti1,2, Wajdi Chermiti1,2, Nader Naouar ${ }^{1,2}$, \\ Mohamed Laziz Ben Ayeche ${ }^{1,2}$
}

${ }^{1}$ Orthopedic Department, Sahloul University Hospital, Sousse, Tunisia

${ }^{2}$ Faculty of Medicine of Sousse, University of Sousse, Sousse, Tunisia

Email: hamdi.kaziz@yahoo.fr

How to cite this paper: Kaziz, H., Triki, M.A., Benzarti, S., Chermiti, W., Naouar, N. and Ben Ayeche, M.L. (2019) Comparison of Reverse Shoulder Arthroplasty and Hemiarthroplasty for Proximal Humeral Fractures: What about Functional Outcome? Reverse versus Hemiarthroplasty in Shoulder Fractures. Open Journal of Orthopedics, 9, 112-122.

https://doi.org/10.4236/ojo.2019.94011

Received: January 20, 2019

Accepted: April 15, 2019

Published: April 18, 2019

Copyright $\odot 2019$ by author(s) and Scientific Research Publishing Inc. This work is licensed under the Creative Commons Attribution International License (CC BY 4.0).

http://creativecommons.org/licenses/by/4.0/

\begin{abstract}
Purpose: Shoulder replacement becomes more indicated in complex fractures of the humeral head. Indications depend on some factors especially age and fracture's pattern. The aim of our study is to compare the functional results of both reverse shoulder arthroplasty (RSA) and hemiarthroplasty (HA) in complex proximal humerus fractures. Materials and Methods: Fifty-two shoulder arthroplasties (20 reverse shoulder arthroplasties, 38 hemiarthroplasties), were reviewed retrospectively, between January 2010, and December, 2015. Preoperative, operative, and postoperative evaluations were achieved based on medical observations. At last follow-up, functional outcomes were established according Constant-Murley Score and American Shoulder and Elbow Surgeons (ASES) score. Complications rates were well-defined and compared between the study groups. Results: The mean of follow-up was 41.5 months. Comparing the study groups, reverse shoulder arthrosplasties were significantly older (mean age: 76.3 versus 66$)$. These fractures occur more in women ( $70 \%$ versus 57\%). At last follow-up, functional outcomes were better in reverse shoulder arthroplasty group (Constant-Murley Score 76 versus 59; ASES score 56 versus 41). The mean anterior elevation and external rotation were better in reverse shoulder arthroplasty respectively $\left(110^{\circ}\right.$ versus $88^{\circ} ; 28^{\circ}$ versus $\left.19^{\circ}\right)$. Revision was more required in hemiarthroplasty group than reverse shoulder arthroplasty group. Conclusion: Reverse shoulder arthroplasty seems to improve functional outcome at intermediate and long-term of follow-up of proximal complex humeral fractures on comparison to hemiarthroplasty.
\end{abstract}




\section{Keywords}

Shoulder, Fracture, Reverse, Hemiarthroplasty, Comparison

\section{Introduction}

Complex fractures of the proximal humerus become more frequent in daily practice, explained by the increasing rate of osteoporosis in actual aging populations [1]. These injuries are considered to be the third fracture of person aged more than 65 year-old [2] [3]. Treatment is still controversial and various options have been described in the literature: none operatively treatment may be used in case of undisplaced or minimally displaced fractures however, surgery is compulsory in displaced fractures [4] [5]. Indications depend on some factors such as: age, arm dominance, patient activity level, presence of other injuries, osteoporosis and fracture's pattern [6]. Shoulder arthroplasty is an option for complex fractures coming in older people with osteoporosis, fracture-dislocations, head-splitting fractures, and fractures involving more than the half of the articular surface [7]. Through the literature, several series were found evaluating functional outcome after both hemiarthroplasty and reverse shoulder arthroplasty but with few comparative studies [8] [9] [10] [11]. The aim of our study was to compare the functional outcome of reverse versus hemiarthroplasty shoulder replacement in complex proximal humeral fractures.

\section{Materials and Methods}

\subsection{Patients}

We have reviewed retrospectively all cases of complex fractures of the humeral head treated with shoulder arthroplasty. All patients were collected between January 1, 2010, to December 31, 2015 in orthopedics department of Sahloul University Hospital. Selection criteria were: complex fractures of the humeral head, no associated injuries of the upper limb and absence of shoulder arthritis. The mean of follow-up was 41.5 months (range: 24 - 96). Two groups had been established based on the type of arthroplasty indicated in each case (group 1: fractures treated with hemiarthroplasty and group 2 treated with reverse shoulder arthroplasty).

\subsection{Assessment}

A comparison of both these groups concerning preoperative characteristics (age, sex, fracture's pattern), operative characteristics (surgical approach, prostheses used), and postoperative outcomes, including Constant-Murley scores and American Shoulder and Elbow Surgeons (ASES) scores were achieved [12] [13]. Post operative elevation, abduction and external rotation were evaluated separately. Complications such as stiffness, nonunion, malunion of tuberosities, infection and the revision rate were revealed and compared between the two 
groups. Baseline demographic, operative and post operative measures were compared between the groups using Fisher exact tests, independent $t$ tests, and Mann-Whitney U tests, as appropriate. A general linear model was used to compare Constant score and ASES score between groups in a multivariate analysis that included age, sex, surgical approach, functional outcome. Complication's rates were compared using Fisher exact tests, and log-rank tests were used to compare revision rates during the entire follow-up period. A two-tailed $\mathrm{p}<$ 0.05 was taken to indicate statistical significance.

\section{Results}

\subsection{Demographic Characteristics}

After reviewing our results, the mean age in reverse shoulder arthroplasty group was significantly higher than the hemiarthroplasty group (76.3 years versus 66; $p$ $=0.002$ ). Women were more concerned by the reverse shoulder arthroplasty than hemiarthroplasty with a significant difference $(70 \%$ versus $57 \% ; \mathrm{p}=0.042)$.

\subsection{Preoperative and Operative Data}

Concerning the fracture's classification, there was no significant difference between the two groups: three-part fracture (40\% versus $47 \% ; \mathrm{p}=0.8)$ and four-part $(60 \%$ versus $53 \%$; $=0.9)$ (Table 1$)$. The choice of the surgical approach has never affected the results since there was no significant difference between the deltopectoral and superolateral approaches in both groups (RSA: $40 \%$ versus $60 \%$; $\mathrm{p}=0.7, \mathrm{HA}: 57 \%$ versus $43 \% \mathrm{p}=0.6$ ). The reconstruction of tuberosities has been established by the same surgical procedure in all cases of both two groups.

\subsection{Functional Outcomes}

Reviewing the functional outcomes at last follow-up, reverse shoulder arthroplasty was better and effective than the hemiarthroplasty in term of decreasing the pain (ASES score was better in reverse shoulder arthroplasty than the hemiarthroplasty: 56 versus $41 ; \mathrm{p}=0.51)$. Moreover, the Constant score was better in reverse shoulder arthroplasty group than in hemiarthroplasty group but this difference was not statistically significant (76 points versus 56 points; $\mathrm{p}=0.052$ ).

Table 1. Preoperative demographic features of RSA and HA groups.

\begin{tabular}{ccc}
\hline & RSA (\%) & HA (\%) \\
\hline Number & 20 & 38 \\
Male & $6(30 \%)$ & $16(42 \%)$ \\
Female & $14(70 \%)$ & $22(58 \%)$ \\
Three-part fracture & 76.3 & 66 \\
Four-part fracture & $8(40 \%)$ & $18(47 \%)$ \\
\end{tabular}


Evaluation of postoperative range of motion has revealed a better results in reverse shoulder arthroplasty than in hemiarthroplasty: the mean active anterior elevation in reverse shoulder arthroplasty group was $111^{\circ}$ compared to $88^{\circ}$ in hemiarthroplasty group; $\mathrm{p}=0.003$. Furthermore, external rotation was little better in reverse shoulder arthroplasty group but without a significant difference $\left(28^{\circ}\right.$ versus $\left.19^{\circ} ; \mathrm{p}=0.6\right)$ however, the mean abduction in reverse shoulder arthroplasty was worse than the hemiarthroplasty group without a statistical significant difference $\left(90^{\circ}\right.$ versus $\left.100^{\circ} ; \mathrm{p}=0.7\right)$ (Table 2$)$.

\subsection{Complications}

Reviewing the tuberosities evolution, we have found that resorption of tuberosities has affected the final outcome especially in terms of external rotation and it was with a statistically significant difference between the two groups: external rotation was more decreased in hemiarthroplasty group explained by the resorption of tuberosities. At the time of follow-up, all complications were revealed: Stiffness was the most reported complication with a difference statistically significant between the two groups (RSA: 15\% versus HA: $18 \%$; $=0.047$ ). Infection rates were similar in two groups without a statistical significant difference between groups $(\mathrm{p}=0.53$ ). Resorption of tuberosities has been found more frequent in hemiarthroplasty group with a significant statistical difference $(18 \%$ versus $10 \% ; \mathrm{p}=0.03$ ) (Table 3 ). Finally, some especial complications for reverse shoulder arthroplasty such as scapular notching, was found in only three cases (15\%): $100 \%$ were grade I. Specific complications of the hemiarthroplasty were well mentioned in (Figure 1).

\section{Discussion}

Management of complex proximal humerus fracture is until now controversial especially in elderly [14]. Several published series have reported the functional outcomes for each type of arthroplasty at short, intermediate and long-term of follow up with a disparity of results [15] [16] [17]. However, the early evaluation of functional outcome has not revealed any difference between ship the two types of shoulder arthroplasty especially before six months postoperatively [18] [19]. In addition, functional outcomes, at intermediate follow-up, in patients treated with hemiarthroplasty had never found a difference to those treaded

Table 2. Functional outcomes of both RSA and HA.

\begin{tabular}{cccc}
\hline Outcome & RSA & HA & p-value \\
\hline ASES pain score (Points) & 56 & 41 & 0.51 \\
Constant -Murley (Points) & 76 & 59 & 0.048 \\
Active abduction $\left({ }^{\circ}\right)$ & 90 & 100 & 0.7 \\
Active anterior elevation $\left({ }^{\circ}\right)$ & 111 & 88 & 0.003 \\
External rotation with arm by side $\left(^{\circ}\right)$ & 28 & 19 & 0.6 \\
\hline
\end{tabular}


Table 3. Complication rates of both RSA and HA.

\begin{tabular}{cccc}
\hline Complications & $\begin{array}{c}\text { Number (\%) of } \\
\text { complications } \\
\text { RSA }\end{array}$ & $\begin{array}{c}\text { Number (\%) of } \\
\text { complications } \\
\text { HA }\end{array}$ & p-value \\
\hline Infection & $1(5)$ & $2(5)$ & 0.53 \\
Hematoma & $2(10)$ & $3(7)$ & 0.63 \\
Resorption & $2(10)$ & $7(18)$ & 0.03 \\
Non union & $2(10)$ & $5(13)$ & 0.04 \\
Mal union & $1(5)$ & $3(7)$ & 0.52 \\
Dislocation & $0(0)$ & $3(7)$ & 0.003 \\
Nerve palsy & $1(5)$ & $2(5)$ & 0.043 \\
Stiffness & $3(15)$ & $7(18)$ & 0.047 \\
Periprosthetic fracture & $0(0)$ & $0(0)$ & 0 \\
\hline
\end{tabular}

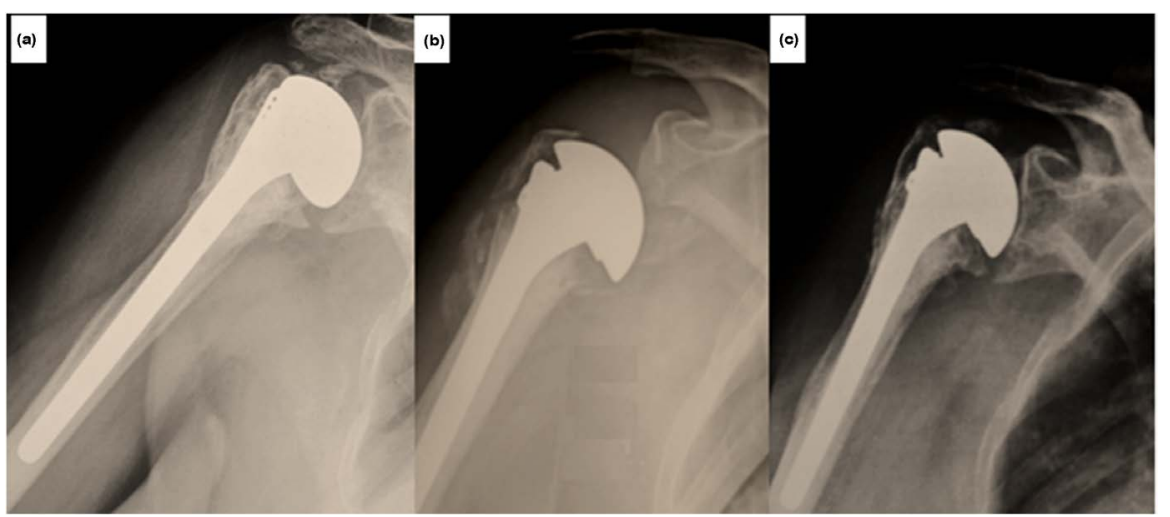

Figure 1. (a) Anteroposterior radiograph indicating glenoid wear after failed hemiarthroplasty; (b) Anteroposterior radiograph indicating non-union of tuberosities; (c) Anteroposterior radiograph indicating a resorption of tuberosities after hemiarthroplasty.

even conservatively or with others devices such as nail or plates a part from fractures morphology, demographic characteristics and surgical approaches. However, the functional results at long-term follow-up were found to be better in reverse shoulder arthroplasty than in hemiarthroplasty group [20] [21] [22]. The authors felt that the good functional outcome seen in their series supported the use of reverse shoulder arthroplasty as a treatment option for elderly patients with complex acute proximal humeral fractures [8]-[23]. Comparative series studying functional results in both hemiarthroplasty and reverse shoulder arthroplasty are rare [24] [25]. The most reported results agreed that functional outcomes at intermediate and long-term follow-up are better than the fractures treated with hemiarthroplasty [26] [27]. In fact, reviewing the literature, the first fractures were treated by hemiarthroplasty: this option needs to respect some obligations such as, tuberosities reconstruction, conservation of the humeral length and ideal retroversion [28] [29]. Whereas, it is so difficult to respect all these details that can lead to an early failure of the surgery [29]. Displacement 
and non-union of tuberosities are the most reported complications after hemiarthroplasty and functional outcomes may be affected by these complications [30]. Through the literature, functional outcomes of hemiarthroplasty, indicated for complex proximal humerus fractures, have been found to be various but several conclusions have been established concerning the relationship between the outcomes and this options: it is well known that the functional outcome depends on the quality of tuberosities reconstruction and the surgical recommendations at the time of hemiarthroplasty procedure: malposition may lead to non union and inferior functional results [30] [31] [32]. Some authors have published superior outcomes after reverse shoulder arthroplasty as compared with hemiarthroplasty; most reports have presented Level-III evidence [9] [30] [31] [32] [33] [34] [35] (Table 4). Obviously, in case of reverse shoulder arthroplasty, functional results were not affected by malunion or nonunion of the tuberosities as much as in case of hemiarthroplasty, in addition, the recovery is obtained quickly without careful mobilization during rehabilitation [33] [34]. As a matter of fact, reverse shoulder arthroplasty represents an excellent solution for elderly patients with cuff tear arthropathy, degenerative arthritis and proximal humeral malunion [31] [32] [35]. Moreover, it is considered as a solution for several problems associated in preoperatively to acute fractures or occurring in postoperatively after hemiarthroplasty as complications [33] [34] [35]. Until now, no prospective randomized trials comparing reverse shoulder arthroplasty with hemiarthroplasty has been published. Some systematic reviews have found that reverse shoulder arthroplasty improves range of motion and functional outcome scores (ASES, Constant-Murley, and Oxford scores), with no difference in the rate of complications comparing to hemiarthroplasty group [34] [35]. On the basis of the current literature, reverse shoulder arthroplasty in acute complex fractures of the humeral head seems to provide satisfied functional outcomes especially at intermediate and long-term follow-up.

Our study has several limitations. Firstly, the patient groups were not equivalent at baseline because they differed with respect to age, sex, and demographic characteristics. Multivariate analyses were performed to adjust the Constant comparison for these potential confounding variables, however, and this had no effect on the significance of the differences between the two patient groups. Secondly, preoperative Constant score was not assessed, which would have assisted interpretation of postoperative function. However, because the patients in our study were all admitted and managed acutely after shoulder trauma, the validity of premorbid shoulder functional assessment is questionable. Thirdly, we don't have preoperative or postoperative radiographic assessment, assessment of associated soft tissue injury, or the specific indications for RSA or hemiarthroplasty in each case, restricting result stratification with respect to fracture severity, soft tissue damage, tuberosities healing, and treatment algorithm. Tuberosities healing are of particular importance, because near-anatomic tuberosities healing in hemiarthroplasty patients has been shown to significantly positively affect 
Table 4. Comparative functional outcomes in both RSA and HA through the literature.

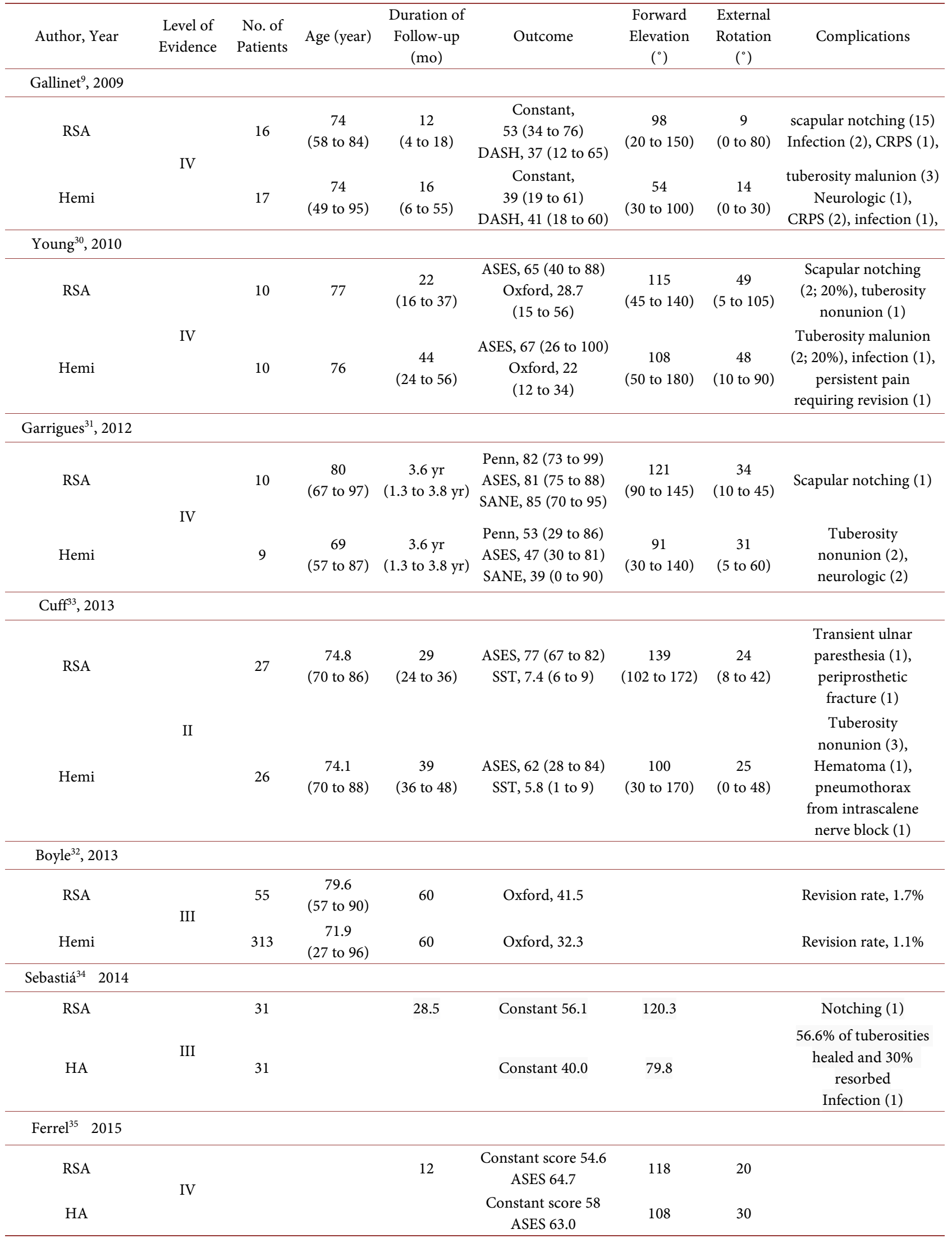


patient outcomes [5]. Fourthly, functional evaluation was restricted to the Constant score, which is purely a subjective scoring system. Objective functional evaluation, with assessment of range of motion and power, would have significantly strengthened our group comparisons.

\section{Conclusion}

Management of acute complex proximal humerus fractures is until now controversial especially in elderly. Shoulder arthroplasty has been considered as a successful option for theses injuries. Series comparing the functional outcomes in both reverse shoulder arthroplasty and hemiarthroplasty are rare. The reported results in literature showed a better pain relief, range of motion and Constant score in reverse shoulder arthroplasty than hemiarthroplasty with a similar complication rates. Our results support reverse shoulder arthroplasty as a successful surgical option for patients with acute proximal humeral fractures requiring prosthetic replacement of the humeral head.

\section{Disclaim}

The authors, their immediate families, and any research foundations with which they are affiliated have not received any financial payments or other benefits from any commercial entity related to the subject of this article.

\section{Conflicts of Interest}

The authors declare no conflicts of interest regarding the publication of this paper.

\section{References}

[1] Baron, J.A., Barrett, J.A. and Karagas, M.R. (1996) The Epidemiology of Peripheral Fractures. Bone, 18, 209-213. https://doi.org/10.1016/8756-3282(95)00504-8

[2] Court-Brown, C.M. and Caesar, B. (2006) Epidemiology of Adult Fractures: 381, a Review. Injury, 37, 691-697. https://doi.org/10.1016/j.injury.2006.04.130

[3] Robinson, P.M., Harrison, T., Cook, A. and Parker, M.J. (2012) Orthopaedic Injuries Associated with Hip Fractures in Those Aged over 60 Years: A Study of Patterns of Injury and Outcomes for 1971 Patients. Injury, 43, 1131-1134. https://doi.org/10.1016/j.injury.2012.03.012

[4] Neer, C.S. (1970) Displaced Proximal Humerus Fractures: I. Classification and Evaluation. The Journal of Bone and Joint Surgery. American Volume, 52, 1077-1089. https://doi.org/10.2106/00004623-197052060-00001

[5] Rasmussen, S., Hvass, I., Dalsgaard, J., Christensen, B.S. and Holstad, E. (1992) Displaced Proximal Humeral Fractures: Results of Conservative Treatment. Injury, 23, 41-43. https://doi.org/10.1016/0020-1383(92)90124-B

[6] Bosch, U., Skutek, M., Fremerey, R.W. and Tscherne, H. (1998) Outcome after Primary and Secondary Hemiarthroplasty in Elderly Patients with Fractures of the Proximal Humerus. Journal of Shoulder and Elbow Surgery, 7, 479-484. https://doi.org/10.1016/S1058-2746(98)90198-7

[7] Mighell, M.A., Kolm, G.P., Collinge, C.A. and Frankle, M.A. (2003) Outcomes of 
Hemiarthroplasty for Fractures of the Proximal Humerus. Journal of Shoulder and Elbow Surgery, 12, 569-577. https://doi.org/10.1016/S1058-2746(03)00213-1

[8] Bufquin, T., Hersan, A., Hubert, L. and Massin, P. (2007) Reverse Shoulder Arthroplasty for the Treatment of Three- and Four-Part Fractures of the Proximal Humerus in the Elderly: A Prospective Review of 43 Cases with a Short Term Follow-Up. Journal of Bone and Joint Surgery, 89, 516-520. https://doi.org/10.1302/0301-620X.89B4.18435

[9] Gallinet, D., Clappaz, P., Garbuio, P., Tropet, Y. and Obert, L. (2009) Three or Four Parts Complex Proximal Humerus Fractures: Hemiarthroplasty versus Reverse Pros-Thesis: A Comparative Study of 40 Cases. Orthopaedics \& Traumatology: Surgery \& Research, 95, 48-55. https://doi.org/10.1016/j.otsr.2008.09.002

[10] Alentorn-Geli, E., Guirro, P., Santana, F. and Torrens, C. (2014) Treatment of Fracture Sequelae of the Proximal Humerus: Comparison of Hemiarthroplasty and Reverse Total Shoulder Arthroplasty. Archives of Orthopaedic and Trauma Surgery, 134, 1545-1550. https://doi.org/10.1007/s00402-014-2074-9

[11] Wall, B., Nove-Josserand, L., O’Connor, D.P., Edwards, T.B. and Walch, G. (2007) Reverse Total Shoulder Arthroplasty: A Review of Results According to Etiology. Journal of Bone and Joint Surgery, 89, 1476-1485. https://doi.org/10.2106/00004623-200707000-00011

[12] Gilbart, M.K. and Gerber, C. (2007) Comparison of the Subjective Shoulder Value and the Constant Score. Journal of Shoulder and Elbow Surgery, 16, 717-721. https://doi.org/10.1016/j.jse.2007.02.123

[13] Michener, L.A., McClure, P.W. and Sennett, B.J. (2002) American Shoulder and Elbow Surgeons Standardized Shoulder Assessment Form, Patient Self-Report Section: Reliability, Validity, and Responsiveness. Journal of Shoulder and Elbow Surgery, 11, 587-594. https://doi.org/10.1067/mse.2002.127096

[14] Zyto, K., Ahrengart, L. and Sperber, A. (1997) Treatment of Displaced Proximal Humeral Fractures in Elderly Patients. Journal of Bone and Joint Surgery, 70, 412-417. https://doi.org/10.1302/0301-620X.79B3.0790412

[15] Kralinger, F., Schwaiger, R., Wambacher, M., Farrell, E., Menth-Chiari, W. and Lajtai, G. (2004) Outcome after Primary Hemiarthroplasty for Fracture of the Head of the Humerus. Journal of Bone and Joint Surgery, 86, 217-219.

https://doi.org/10.1302/0301-620X.86B2.14553

[16] Neer 2nd CS (1970) Displaced Proximal Humeral Fractures. II. Treatment of Three-Part and Four-Part Displacement. Journal of Bone and Joint Surgery, 52, 1090-1103. https://doi.org/10.2106/00004623-197052060-00002

[17] Sirveaux, F., Roche, O. and Molé, D. (2010) Shoulder Arthroplasty for Acute Proximal Humerus Fracture. Orthopaedics \& Traumatology: Surgery \& Research, 96, 683-694. https://doi.org/10.1016/j.otsr.2010.07.001

[18] Obert, L., Saadnia, R., Tournier, C., Bonnevialle, N., Saragaglia, D. and Sirveaux, F. (2016) Four-Part Fractures Treated with Reversed Total Shoulder Prosthesis: Prospective and Retrospective Multicenter Study. Results and Complications. Orthopaedics \& Traumatology: Surgery \& Research, 102, 279-285. https://doi.org/10.1016/j.otsr.2016.01.019

[19] Boileau, P., Moineau, G., Brassart, N., Clavert, P., Favard, L. and Sirveaux, F. (2010) Reverse Shoulder Fracture Prothesis for the Treatment of Proximal Humeral Fractures in Elderly Patients: Early Clinical and Radiological Results. Shoulder Concept 2010: Arthroscopy and Arthroplasty. Sauramps Medical, 231-243.

[20] Cazeneuve, J.F. and Cristofari, D.J. (2011) Long Term Functional Outcome Follow- 
ing Reverse Shoulder Arthroplasty in the Elderly. Orthopaedics \& Traumatology: Surgery \& Research, 97, 583-589. https://doi.org/10.1016/j.otsr.2011.03.025

[21] Cazeneuve, J.F. and Cristofari, D.J. (2014) Grammont Reversed Prosthesis for Acute Complex Fracture of the Proximal Humerus in an Elderly Population with 5 to 12 Years Follow-Up. Orthopaedics \& Traumatology: Surgery \& Research, 100, 93-97. https://doi.org/10.1016/j.otsr.2013.12.005

[22] Guery, J., Favard, L., Sirveaux, F., Oudet, D., Mole, D. and Walch, G. (2006) Reverse Total Shoulder Arthroplasty. Survivorship Analysis of Eighty Replacements Followed for Five to Ten Years. Journal of Bone and Joint Surgery, 88, 1742-1747. https://doi.org/10.2106/JBJS.E.00851

[23] Bonnevialle, N., Tournier, C., Clavert, P., Ohl, X., Sirveaux, F. and Saragaglia, D. (2016) Hemiarthroplasty versus Reverse Shoulder Arthroplasty in 4-Part Displaced Fractures of the Proximal Humerus: Multicenter Retrospective Study. Orthopaedics \& Traumatology: Surgery \& Research, 102, 569-573. https://doi.org/10.1016/j.otsr.2016.02.014

[24] Valenti, P., Katz, D., Kilinc, A., Elkholti, K. and Gasiunas, V. (2012) Mid-Term Outcome of Reverse Shoulder Prostheses in Complex Proximal Humeral Fractures. Acta Orthopaedica Belgica, 78, 442-449.

[25] Gallinet, D., Adam, A., Gasse, N., Rochet, S. and Obert, L. (2013) Improvement in Shoulder Rotation in Complex Shoulder Fractures Treated by Reverse Shoulder Arthroplasty. Journal of Shoulder and Elbow Surgery, 22, 38-44. https://doi.org/10.1016/j.jse.2012.03.011

[26] Mattiassich, G., Marcovici, L.L., Krifter, R.M., Ortmaier, R., Wegerer, P. and Kroepfl, A. (2013) Delta III Reverse Shoulder Arthroplasty in the Treatment of Complex 3- and 4-Part Fractures of the Proximal Humerus: 6 to 42 Months of Follow-Up. BMC Musculoskeletal Disorders, 14, 1-10.

https://doi.org/10.1186/1471-2474-14-231

[27] Boileau, P., Winter, M., Cikes, A., Han, Y., Carles, M., Walch, G., et al. (2013) Can Surgeons Predict What Makes a Good Hemiarthroplasty for Fracture? Journal of Shoulder and Elbow Surgery, 22, 1495-1506. https://doi.org/10.1016/j.jse.2013.04.018

[28] Reuther, F., Mühlhäusler, B., Wahl, D. and Nijs, S. (2010) Functional Outcome of Shoulder Hemi-Arthroplasty for Fractures: A Multicentre Analysis. Injury, 41, 606-612. https://doi.org/10.1016/j.injury.2009.11.019

[29] Boileau, P., Krishnan, S.G., Tinsi, L., Walch, G., Coste, J.S. and Mole, D. (2002) Tuberosity Malposition and Migration: Reasons for Poor Outcomes after Hemiarthroplasty for Displaced Fractures of the Proximal Humerus. Journal of Shoulder and Elbow Surgery, 11, 401-412. https://doi.org/10.1067/mse.2002.124527

[30] Young, S.W., Segal, B.S., Turner, P.C. and Poon, P.C. (2010) Comparison of Functional Outcomes of Reverses Shoulder Arthroplasty versus Hemiarthroplasty in the Primary Treatment of Acute Proximal Humerus Fracture. ANZ Journal of Surgery, 80, 789-793. https://doi.org/10.1111/j.1445-2197.2010.05342.x

[31] Garrigues, G.E., Johnston, P.S., Pepe, M.D., Tucker, B.S., Ramsey, M.L. and Austin, L.S. (2012) Hemiarthroplasty versus Reverse Total Shoulder Arthroplasty for Acute Proximal Humerus Fractures in Elderly Patients. Orthopedics, 35, e703-e708. https://doi.org/10.3928/01477447-20120426-25

[32] Boyle, M.J., Youn, S.M., Frampton, C.M. and Ball, C.M. (2013) Functional Outcomes of Reverse Shoulder Arthroplasty Compared with Hemiarthroplasty for Acute Proximal Humeral Fractures. Journal of Shoulder and Elbow Surgery, 22, 
32-37. https://doi.org/10.1016/j.jse.2012.03.006

[33] Cuff, D.J. and Pupello, D.R. (2013) Comparison of Hemiarthroplasty and Reverse Shoulder Arthroplasty for the Treatment of Proximal Humeral Fractures in Elderly Patients. Journal of Bone and Joint Surgery, 95, 2050-2055.

https://doi.org/10.2106/JBJS.L.01637

[34] Sebastiá, F., Cebrián, G., Lizaur, U. and Gil, G. (2014) Reverse Shoulder Arthroplasty versus Hemiarthroplasty for Acute Proximal Humeral Fractures. A Blinded, Randomized, Controlled, Prospective Study. Journal of Shoulder and Elbow Surgery, 23, 1419-1426. https://doi.org/10.1016/j.jse.2014.06.035

[35] Ferrel, J.R., Trinh, T.Q. and Fischer, R.A. (2015) Reverse Total Shoulder Arthroplasty versus Hemiarthroplasty for Proximal Humeral Fractures: A Systematic Review. Journal of Orthopaedic Trauma, 29, 60-68.

https://doi.org/10.1097/BOT.0000000000000224 